they can appear in the lung, heart, larynx and Achilles tendon [2]. Methotrexate nodulosis is rare in patients with rheumatoid arthritis who are negative for rheumatoid factor [3]. Nodules often, but not always, regress or disappear on discontinuing the drug [3].

Methotrexate nodulosis in conditions other than rheumatoid arthritis is very rare. It has been reported in a patient with systemic lupus erythematosus and Jaccoud's arthropathy [4], a patient with juvenile arthritis who was rheumatoid factor negative [5], and a patient with psoriatic arthritis and negative rheumatoid factor [6]. Only the patient with juvenile arthritis had pulmonary nodules. However, a recent case report describes a patient similar to ours with psoriatic arthritis and negative rheumatoid factor who developed accelerated pulmonary nodulosis and a sterile pleural effusion after treatment with methotrexate [7]. Open lung biopsy showed histology compatible with a rheumatoid nodule. The nodules resolved on stopping methotrexate treatment.

\author{
A. Manuel ${ }^{*}$, Q. Jones ${ }^{\#}$ and J. Wiggins ${ }^{\#}$ \\ *Churchill Hospital, Oxford, and "Heatherwood and Wexham \\ Park Hospital, Slough, UK.
}

Correspondence: A. Manuel, Churchill Hospital, Old Road, Headington, Oxford, OX3 7LJ, UK. E-mail: arimanuel1979@ yahoo.co.uk
Statement of Interest: None declared.

Provenance: Submitted article, peer reviewed.

\section{REFERENCES}

1 Di Francesco L, Miller F, Greenwald RA. Detailed immunohistologic evaluation of a methotrexate-induced nodule. Arch Pathol Lab Med 1994; 118: 1223-1225.

2 Kremer JM, Lee JK. The safety and efficacy of the use of methotrexate in long-term therapy for rheumatoid arthritis. Arthritis Rheum 1986; 29: 822-831.

3 Patatanian E, Thompson DF. A review of methotrexate-induced accelerated nodulosis. Pharmacotherapy 2002; 22: 1157-1162.

4 Rivero MG, Salvatore AJ, Gomez-Puerta JA, et al. Accelerated nodulosis during methotrexate therapy in a patient with systemic lupus erythematosus and Jaccoud's arthropathy. Rheumatology 2004; 43: 1587-1588.

5 Falcini F, Taccetti G, Ermini M, et al. Methotrexate-associated appearance and rapid progression of rheumatoid nodules in systemiconset juvenile rheumatoid arthritis. Arthritis Rheum 1997; 40: 175-178.

6 Berris B, Houpt JB, Tenenbaum J. Accelerated nodulosis in a patient with psoriasis and arthritis during treatment with methotrexate. J Rheumatol 1995; 22: 2359-2360.

7 Balbir-Gurman A, Guralnik L. Accelerated pulmonary nodulosis and sterile pleural effusion in a patient with psoriatic arthropathy during methotrexate therapy: a case report. J Clin Rheumatol 2009; 15: 29-30.

DOI: $10.1183 / 09059180.00001210$

\title{
Talcosis due to abundant use of cosmetic talcum powder
}

\section{To the Editor:}

A 36-yr-old, nonsmoking, Hindustan female presented with complaints of dyspnoea without coughing which had persisted for several months. The complaints started after a bout of pneumonia a few months previously. Her medical history was unremarkable. She did not suffer from asthma, nor did asthma run in the family. She worked at an administrative office. Physical examination showed no abnormalities; in particular, the auscultation of the lungs was normal. A screening laboratory examination, including complete blood count, renal function and liver function tests, was normal. A chest radiograph showed nodular lesions in both lungs (fig. 1a).

Because of the abnormal chest radiograph, a second patient history was carried out and revealed a remarkable twice daily bathing ritual where she used large amounts of cosmetic talcum powder. After bathing the patient powdered her whole body with talcum powder, a ritual she had carried out since her childhood. Ancillary laboratory investigations including angiotensin converting enzyme, total immunoglobulin E and anti-cyclic citrullinated peptide were all negative. A high-resolution computed tomography (CT) scan of the thorax showed a diffuse nodular image in both lungs. Interlobular septa and pleura showed a normal pattern (fig. 1b). Pulmonary function tests showed a restrictive pattern, with a normal diffusion capacity. Bronchoscopy did not reveal any endobronchial abnormalities. Bronchoalveolar lavage was negative for mycobacteria and other infectious agents, and no neoplastic cells were found. Inflammatory cell distribution was normal, including a CD4/CD8 ratio of 0.9 (normal $<2.5$ ). Transbronchial lung biopsies showed patchy peribronchiolar fibrosis and an extensive non-caseating granulomatous inflammation with numerous multinucleair giant cells associated with the massive presence of needle-shaped birefringent crystalline material (fig. $2 \mathrm{a}$ and b). Pulmonary vessels showed no abnormalities. No asbestos bodies were observed.

For tissue analysis by energy-dispersive X-ray spectroscopy (EDX), haematoxylin and eosin stained sections of paraffin embedded lung specimens were screened for birefringent crystals. Small areas were chosen from the paraffin blocks, dissected, de-paraffinised and then embedded in Epon according to Luft's procedure (Merck, Darmstadt, Germany). Ultra-thin sections $(200 \mathrm{~nm})$ were cut on an ultra-microtome (Leica Microsystems, Wetzlar, Germany) and examined in a 
1200 EXII electronmicroscope (Jeol, Tokyo, Japan). For generation of the EDX spectra, the scanning transmission electron microscope mode was used. Spectra of the chosen areas were generated with the point and shoot utility using the tracor northern system 6 detector (Thermo Noran, Middleton, WI, USA). Ultra structural examination of these birefringent crystals was performed in the electronmicroscope (1200EX II; Jeol) for morphology, localisation and diffraction pattern. Extracellular sheets and fibres were found in extensive amounts (fig. 2c). EDX analysis of the crystals in the lung biopsy specimen showed particles of magnesium, silicon and sporadical chlorine. The structure of these particles, together with the presence of magnesium and silicon, was consistent with talc (fig. 2d).

Based on the patient's history and the clinical, radiological, histological and mineralogical findings, and by the exclusion of
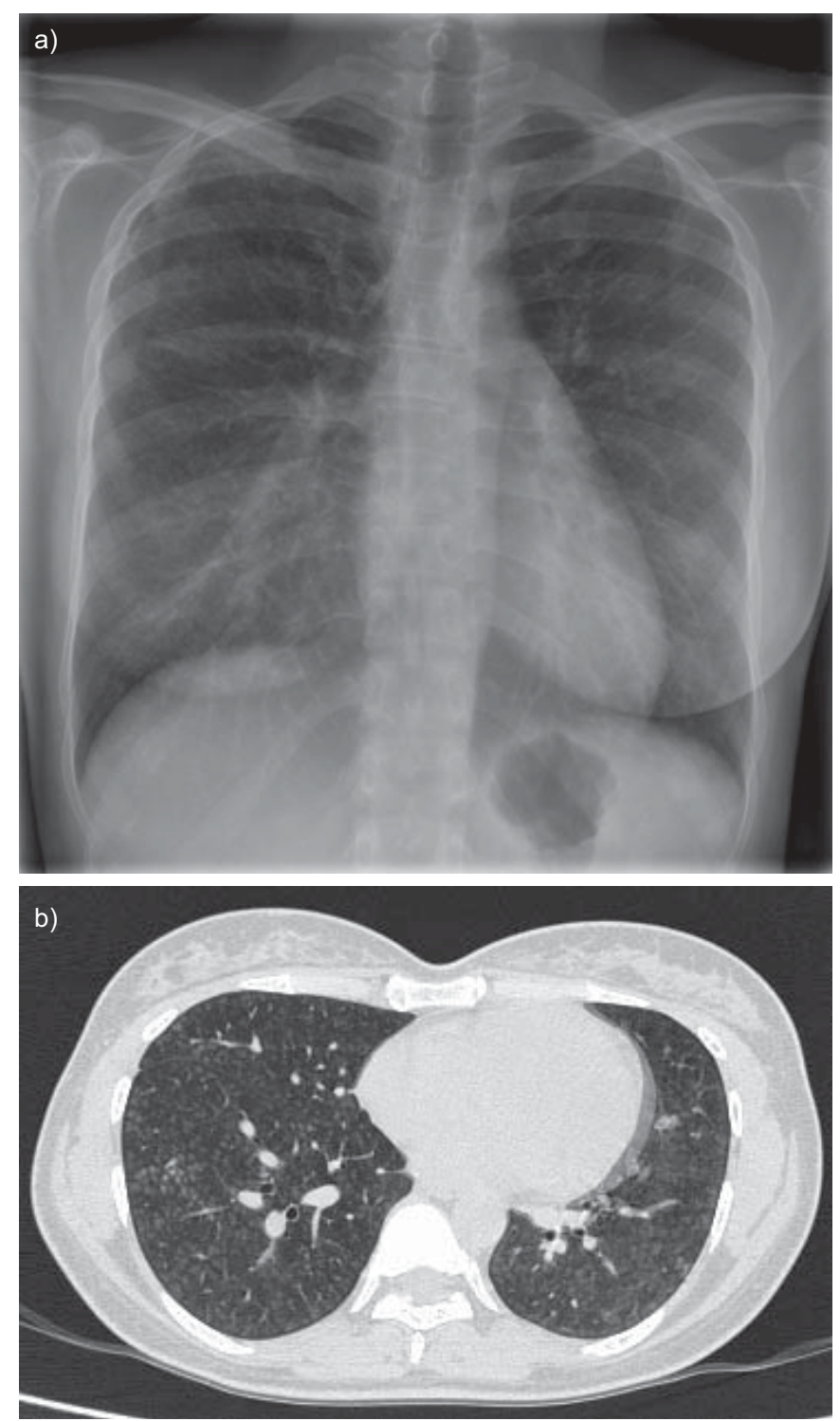

FIGURE 1. Radiodiagnostic imaging. a) A chest radiograph showing multiple nodular lesions in both lungs. b) A high-resolution computed tomography scan showing a diffuse nodular image in both lungs. Interlobular septa and pleura were normal. other plausible causes, the diagnosis of talc induced interstitial lung disease (talcosis) was made based on abundant use of cosmetic talcum powder. At 1-yr follow-up the patient had discontinued her bathing ritual; the complaints had decreased and pulmonary function had increased. The chest radiograph did not show an improvement and the nodular lesions in both lungs remained unchanged.

Pulmonary disease due to talc is almost exclusively encountered secondary to occupational exposure or intravenous drug abuse. Talcosis or talc pneumoconiosis is one of the rarer forms of silicate induced lung disease. It has been described in workers exposed to talc during its production or its industrial use. Very often, the history of exposure is not recognised by the patient. However, talcosis can also be caused due to the use of cosmetic talcum powder. High-purity talc is used in cosmetic and pharmaceutical industries and there is no conclusive evidence that cosmetic talc, when used as intended, presents a health hazard [1].

In 1979 WeLLs et al. [2] described a case which shows remarkable parallels with this case report. The patient was in the habit of dusting the whole body with talc at least once daily and the talc had been applied in a small unventilated room likely to favour inhalation [2]. However, it was THOREL [3] who reported the first case of talc pneumoconiosis in 1896. Following this there have been several written reports of talcosis due to cosmetic talcum powder; however, the course can be quite different [4-9]. Despite these reports the prevalence of talcosis due to the abundant use of cosmetic talcum powder is not as high as could be expected according to the common use of cosmetic talcum powder.

Radiographic findings may include generalised haziness, nodulation and reticulation similar to those observed in asbestosis, but the apices and costophrenic sulci are generally spared in talcosis. As in other forms of pneumoconiosis, nodule confluence results in large opacities that resemble those in progressive massive fibrosis. In some patients, hilar lymphadenopathy develops. High-resolution CT scan findings in patients with talcosis caused by inhaled particulates include small centrilobular and subpleural nodules and heterogeneous conglomerate masses with internal foci of high attenuation that are consistent with talc deposition [10]. In our patient, the size and location of the nodules supports the diagnosis of talcosis.

Apart from a patient history, a biopsy is necessary to make the diagnosis. The pathological features of talc inhalation have been described as either fibrosis reaction, which can be diffuse interstitial or irregular nodular, or as non-caseating granulomatous reaction. Microscopic examination under polarised light reveals birefringent needle-shaped particles in multinucleated giant cells and macrophages. These pathological features differ from pulmonary findings seen after intravenous talc injection. In pulmonary findings seen after intravenous talc injection the particles are larger and characteristic intravascular and perivascular granulomas can be seen [4]. In our patient, the size of the particles, the location of the granulomas and the lack of intravascular and perivascular lesions support inhalation as mode of entry of the talc into the lungs.

This case emphasises the importance of a thorough medical history. On basis of the patient's history and the compatible 

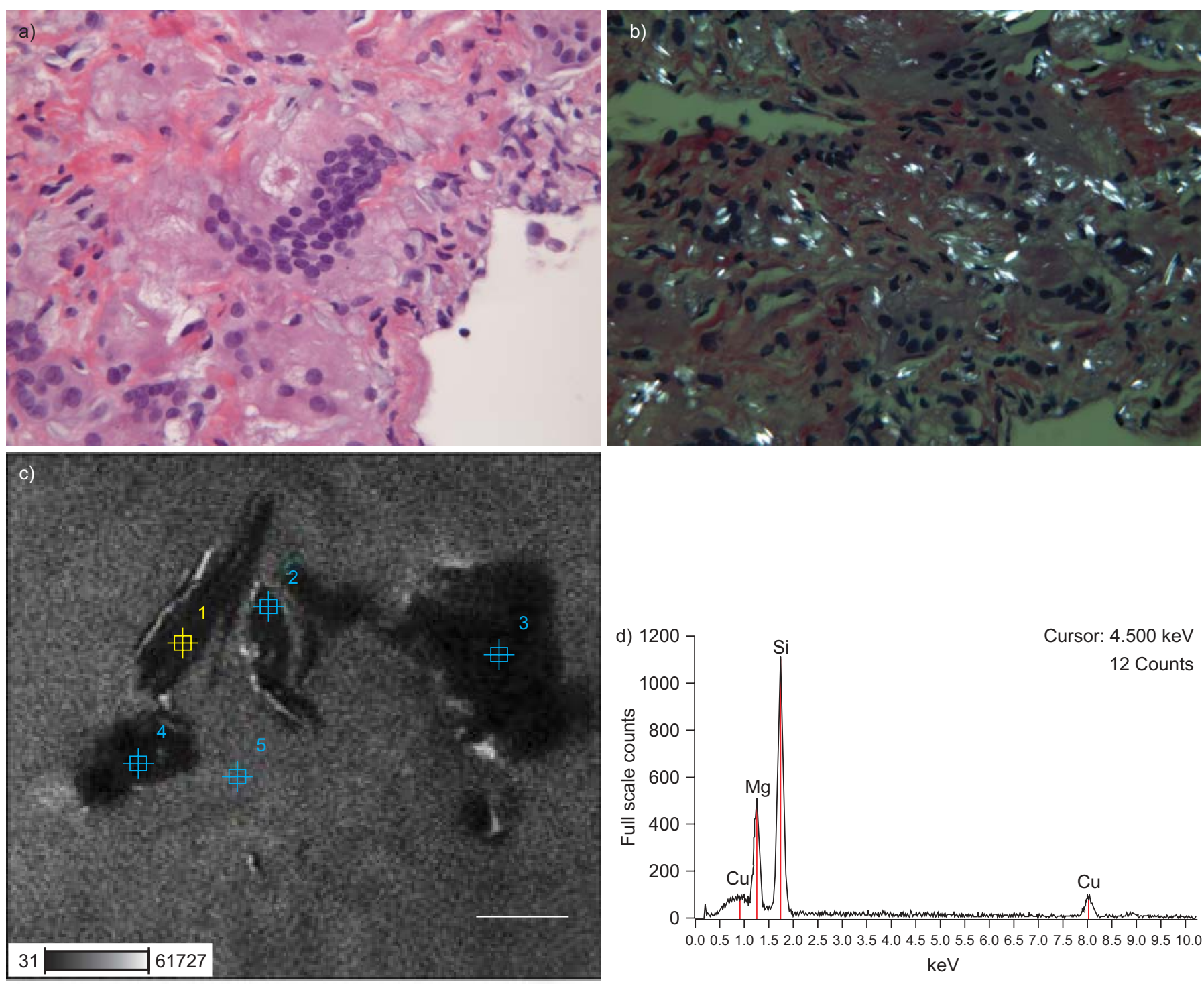

FIGURE 2. Transbronchial lung biopsy microscopic slide of a) lung tissue showing a granulomatous inflammation with giant cell reaction and b) lung tissue under polarised light (birefringed crystalline material). c) Scanning transmission electron micrograph of the lung biopsy specimen showing sheets and fibres. In this area five different points were selected with the point and shoot utility. Points 1-4: electron dense crystalline material; point 5: control area. Scale bar=100 nm. d) Energy-dispersive spectroscopy spectrum of point 1, all crystals in the lung biopsy specimen showed peaks for magnesium (Mg) and silicon (Si) in a ratio consistent with talc. Reference measurements such as point 5, however, only showed peaks for copper (Cu), originating from the copper carrier grid.

clinical, radiological, histological and mineralogical findings, as well as the exclusion of other plausible causes, a diagnosis of talcosis due to abundant cosmetic talcum powder was made.

\section{A. van Huisstede*, V. Noordhoek Hegt", I. Otte-Holler", M.} Looijen-Salamon" and A. Rudolphus*

*Depts of Pulmonology, "Pathology (Pathan), Sint Francisus Gasthuis, Rotterdam, and "Dept of Pathology, Radboud University Nijmegen Medical Centre, Nijmegen, The Netherlands.

Correspondence: A. van Huisstede, Dept of Pulmonology, Sint Franciscus Gasthuis, Kleiweg 500, 3045 PM, Rotterdam, The Netherlands. E-mail: a.vanhuisstede@sfg.nl
Statement of Interest: None declared.

Provenance: Submitted article, peer reviewed.

\section{REFERENCES}

1 Wehner A. Biological effects of cosmetic talc. Food Chem Toxicol 1994; 32: 1173-1184.

2 Wells IP, Dubbins PA, Whimster WF. Pulmonary disease caused by the inhalation of cosmetic talcum powder. Br J Radiol 1979; 52 : 586-588.

3 Thorel C. Talc lung: a contribution to the pathological anatomy of pneumoconiosis. Beitr Pathol Anat Allgem Pathol 1896; 20: 85-101.

4 Dekel Y, Rath-Wolfson L, Rudniki C, et al. Talc inhalation is a lifethreatening condition. Pathol Oncol Res 2004; 10: 231-233. 
5 Egan AJ, Tazelaar HD, Myers JL, et al. Munchausen syndrome presenting as pulmonary talcosis. Arch Pathol Lab Med 1999; 123: 736-738.

6 Abraham JL, Brambilla C. Particle size for differentiation between inhalation and injection pulmonary talcosis. Environ Res 1980; 21 : 94-96.

7 Cotton WH, Davidson PJ. Aspiration of baby powder. N Engl J Med 1985; 313: 1662.
8 Hollinger MA. Pulmonary toxicity of inhaled and intravenous talc. Toxicol Lett 1990; 52: 121-127.

9 Nam K, Gracey DR. Pulmonary talcosis from cosmetic talcum powder. JAMA 1972; 221: 492-493.

10 Chong S, Lee KS, Chung MJ, et al. Pneumoconiosis: comparison of imaging and pathologic findings. Radiographics 2006; 26: 59-77.

DOI: $10.1183 / 09059180.00001310$ 